\title{
Ensino de Comportamento Verbal Elementar por Exemplares Múltiplos em Crianças com Autismo
}

\author{
Bárbara Trevizan Guerra ${ }^{1}$ \\ ${ }^{1}$ Universidade Estadual Paulista Júlio de Mesquita \\ Filho, SP, Brasil.
}

\author{
Ana Cláudia Moreira Almeida Verdu² \\ ${ }^{2}$ Universidade Estadual Paulista Júlio de Mesquita \\ Filho, SP, Brasil
}

\begin{abstract}
Resumo: No escopo da investigação de sob quais condições ocorre a aprendizageme a emergência de operantes verbais, diferentes condições de ensino têm sido planejadas. Considerando que a população com Transtorno do Espectro Autista (TEA) apresenta frequentemente um repertório de operantes verbais ausente ou fracamente estabelecido, é necessário o estudo do planejamento de intervenções sistemáticas desses repertórios com condições de favorecer não só a aquisição de vocabulário, mas também o seu potencial gerativo de novas funções verbais. O Multiple Exemplar Instruction (MEI) é uma estrutura de ensino que tem demonstrado resultados promissores pela sua capacidade de estabelecer relações entre comportamentos de ouvinte e de falante e gerar novas respostas verbais. O objetivo deste estudo foi verificar os efeitos do MEI sobre o estabelecimento e integração entre os repertórios de ouvinte e de falante (ecoico, tato e mando). Participaram duas crianças com TEA, com idades de 7 e 8 anos e cuja comunicação era muito restrita e baseada em trocas de figuras. $\mathrm{O}$ ensino adotou três conjuntos com três estímulos cada. $\mathrm{O}$ ensino com cada conjunto foi realizado separadamente. Ora o ensino consistia no treino de ouvinte baseado em seleção, ora tentativas de ouvinte, ecoico, tato e mando, eram apresentadas de forma rotativa. Sondas múltiplas intercalaram os ensinos e verificaram os efeitos destes sobre o repertório de falante com os demais conjuntos. Os resultados demonstraram um aumento na emissão de respostas de ouvir e falar após o ensino por MEI para os dois participantes, ambos com repertório verbal restrito, mas o procedimento foi mais efetivo para uma das crianças.
\end{abstract}

Palavras-chave: Instrução por Exemplares Múltiplos, Transtorno do Espectro do Autismo, Comportamento Verbal, Ensino.

\section{Teaching Elementary Verbal Behavior by Multiple Exemplar in Children with Autism}

\begin{abstract}
In the scope of research about under what conditions the learning and emergency of verbal operants occurs, different teaching conditions have been planned. Considering that the population with Autistic Spectrum Disorder (ASD) often has a repertoire of verbal operants absent or poorly established, it is necessary to study the planning of systematic interventions in these repertoires with conditions to favor not only vocabulary acquisition, but also their generative potential of new verbal functions. The Multiple Exemplar Instruction (MEI) is a teaching structure that has shown promising results for its ability to establish relationships between listening and speaker behaviors and to generate new verbal responses. The objective of this study was to verify the effects of the MEI on the establishment and integration between the listener repertoires and the speaker (echoic, tact and mand). Two children with ASD, aged between 7 and 8 years old, participated in the study, whose communication was very restricted and based on exchanges of figures. The
\end{abstract}


teaching adopted three sets with three stimuli each. Teaching with each set was carried out separately. The teaching consisted of the training of listener based on selection, sometimes attempts of listener, echoic, tact and mand, were presented in a rotating way. Multiple probes intercalated the teachings and verified the effects of these on the repertoire of speaker with the other sets. The results showed an increase in the emission of listening and speaking responses after MEI teaching for the two participants, both with restricted verbal repertoire, but the procedure was more effective for one of the children.

Keywords: Multiple Exemplar Instruction, Autism Spectrum Disorder, Verbal Behavior, Teaching.

\title{
Enseñanza del Comportamiento Verbal Elemental Mediante Múltiples Copias en Niños con Autismo
}

\begin{abstract}
Resumen: El el ámbito de la investigación de en qué condiciones se produce el aprendizaje y la aparición de operantes verbales, se han planificado diferentes condiciones de enseñanza. Teniendo en cuenta que la población con Trastorno del Espectro Autista (TEA) con frecuencia presenta un repertorio de operantes verbales ausentes o débilmente establecidos, es necesario estudiar la planificación de intervenciones sistemáticas en estos repertorios con condiciones para favorecer no solo la adquisición de vocabulario, sino también su potencial generativo de nuevas funciones verbales. La Instrucción Ejemplar Múltiple (MEI) es una estructura de enseñanza que ha mostrado resultados prometedores por su capacidad para establecer relaciones entre los comportamientos del oyente y el hablante y generar nuevas respuestas verbales. El objetivo de este estudio fue verificar los efectos del MEI en el establecimiento e integración entre los repertorios de oyentes y hablantes (eco, tacto y comando). Participaron dos niños con TEA, de 7 y 8 años, cuya comunicación era muy restringida y basada en intercambios de figuras. La enseñanza adoptó tres conjuntos con tres estímulos cada uno. La enseñanza con cada conjunto se llevó a cabo por separado. Algunas veces la enseñanza consistía en entrenar al oyente en base a la selección, a veces los intentos de escuchar, eco, tacto y comando, se presentaban de manera rotativa. Múltiples sondas intercalan las enseñanzas y verifican sus efectos en el repertorio de los hablantes con los otros grupos. Los resultados mostraron un aumento en la emisión de respuestas para escuchar y hablar después de la enseñanza de MEI para ambos participantes, ambos con repertorio verbal restringido, pero el procedimiento fue más efectivo para uno de los niños.
\end{abstract}

Palabras clave: Instrucción por Múltiples Copias, Trastorno del Espectro del Autismo, Comportamiento Verbal, Enseñanza.

No escopo da investigação de sob quais condições ocorre a aprendizagem e a emergência de operantes verbais, diferentes condições de ensino têm sido planejadas. Considerando que a população com Transtorno do Espectro Autista (TEA) apresenta frequentemente um repertório de operantes verbais ausente ou fracamente estabelecido, é necessário o estudo do planejamento de intervenções sistemáticas desses repertórios com condições de favorecer não só a aquisição de vocabulário, mas também o seu potencial gerativo de novas funções verbais.
O TEA compromete o desenvolvimento infantil de maneira global e, embora a incidência esteja aumentando ao longo dos últimos anos, a causa continua sem ser definida (Matson, \& Kozlowski, 2011). O quadro é composto por déficits e excessos comportamentais nas áreas de Interação/Comunicação Social e Padrões restritos e repetitivos de comportamento, interesse ou atividade (American Psychiatric Association, 2013) e o diagnóstico é realizado por avaliação comportamental.

Os prejuízos ocasionados pelo TEA são passíveis de mudanças por meio de cuidados planejados 
e interações construídas nos ambientes físico e social (Green, 2001). Considerando-se os atrasos no desenvolvimento nas áreas da linguagem, social e comportamentos (restritos e repetitivos), os déficits no comportamento verbal podem ser considerados um dos mais cruciais, uma vez que impossibilitam o desenvolvimento de outras habilidades, como acadêmicas, interações sociais e o brincar (Hartman, \& Klatt, 2005; Nunes,1992).

O comportamento verbal é estabelecido e mantido por contingências de reforço social (Skinner, 1957). Skinner definiu os operantes verbais a partir da sua função e relações de controle que estabelece com estímulos antecedentes. Neste trabalho serão abordados comportamento ecoico, tato e mando em decorrência da sua importância no desenvolvimento verbal e estabelecimento de novos repertórios verbais. Ainda que a definição de comportamento verbal não se restrinja à topografia vocal e considere as diferentes topografias de respostas verbais (vocal, gestual, motora) e diferentes controles de estímulos (táteis, auditivos, visuais), neste trabalho serão consideradas as respostas vocais e estímulos antecedentes auditivos e visuais.

O ecoico é a repetição com correspondência ponto a ponto de um estímulo auditivo, sendo uma resposta verbal vocal controlada pelo estímulo discriminativo verbal auditivo (emitido por alguém); há necessariamente uma identidade estrutural entre ambos; pode ser apresentado desde no estágio inicial do desenvolvimento e é mantido por reforçadores sociais, como a aprovação (Skinner, 1957).

$\mathrm{O}$ tato caracteriza-se por ser uma resposta verbal sob controle de estímulos discriminativos não verbais públicos ou privados (objeto, eventos, sensações); se mantém por consequências sociais quando há identidade funcional, culturalmente estabelecida, entre o estímulo discriminativo e a resposta. Nesse caso, o ouvinte entra em contato com o que controla o comportamento verbal do falante (Skinner, 1957).

O mando caracteriza-se por ordens, pedidos, conselhos, avisos que são emitidos sob uma condição de privação ou estimulação aversiva na qual se explicita os reforçadores a serem providos pelo ouvinte na própria resposta emitida pelo falante. É uma reposta verbal sob controle de estímulos encobertos, mantida por consequências mediadas pelo ouvinte e que foram solicitadas pelo falante (Skinner, 1957).
O comportamento de ouvinte é governado pelo comportamento do falante e é fundamental para a aprendizagem de funções verbais elementares (e.g. ecoicos, tatos, mandos) e outros comportamentos mais complexos denominados comportamento social (Greer, \& Ross, 2008; Novak, \& Pelaez, 2004) tal como conversação, nomeação, correspondência entre falar e fazer, leitura com compreensão, resolução de problemas e reforçamento do comportamento do falante pelo ouvinte em situações de interação social (Greer, \& Ross 2008). Indivíduos que se comportam como ouvintes são essenciais para a comunidade verbal, pois sem eles o comportamento do falante não seria selecionado e fortalecido (Skinner, 1957). O ouvir pode ser avaliado a partir de respostas de seleção de estímulos visuais controladas por estímulos auditivos (Michael, 1985).

Embora seja possível observar uma estreita relação entre os repertórios de ouvinte e falante, a aquisição de ambos ocorre de forma independente, isto é, são funcionalmente independentes, uma vez que a aprendizagem de um repertório não implica na aquisição do outro (Ahearn, 2012; Skinner, 1957).

Considerando que a aprendizagem dos operantes verbais ocorre de forma independente inicialmente, 0 controle de uma resposta verbal por múltiplos estímulos tal como a mesma topografia vocal (por exemplo: dizer "peteca"), mas com funções verbais distintas (por exemplo: função de tato, ecoico ou mando) e as extensões do comportamento de ouvinte para o de falante (por exemplo: ouvir uma palavra nova na presença de um objeto e, posteriormente, passar a nomear esse objeto) podem requerer planejamento especial para crianças com atrasos na linguagem (Greer, \& Ross, 2008; Greer, Stolfi, Chavez-Brown, \& Rivera-Valdes, 2005; Guess, 1969). Nesse sentido, pesquisas têm demonstrado que a aprendizagem de um operante (ouvir) tem efeito sobre a aprendizagem de outro, de topografia e função distintas (falar), somente após o arranjo particular de contingências de ensino, ainda que não haja treino direto das relações-alvo (Fiorile, \& Greer, 2007; Greer et al., 2005; Ribeiro, Elias, Goyos, \& Miguel, 2010).

Essas condições particulares podem estar presentes no estabelecimento da bidirecionalidade observada entre os repertórios de ouvinte e de falante, e serem obtidas pelo Multiple Exemplar Instruction (MEI). No MEI vários operantes são ensinados na mesma sessão, estruturados de forma rotativa e com 
solicitação de diferentes tipos de respostas (como ouvir baseado em seleção, oralizações) e com diferentes controles de estímulos (figuras, palavras ditadas, palavras escritas) (Greer, \& Ross, 2008).

Há diversos estudos que demonstram resultados promissores de aprendizagem utilizando esse procedimento e seu poder gerativo de comportamento verbal, resultando na emergência de diferentes funções verbais, em pessoas com desenvolvimento típico (Greer et al., 2007), em pessoas com deficiência como TEA (Luke, Greer, \& Keohane, 2011; Nuzzolo-Gomez, \& Greer, 2004), deficiência auditiva (Pereira, Assis, Palheta Neto, \& Almeida-Verdu, 218; Rique, Guerra, Borelli, Oliveira, \& Almeida-Verdu, 2017) e para ensino de habilidades mais complexas, como uso de verbos regulares e irregulares (Greer, Yuan, \& Gautreaux, 2005).

Em relação às pesquisas que utilizaram o MEI, diversos autores realizaram estudos com crianças com desenvolvimento atípico que apresentavam repertório básico de ouvinte e falante (Fiorile, \& Greer, 2007; Greer et al., 200,, 2007; Santos, \& Souza, 2016). Esses estudos, de forma geral, obtiveram como resultado a aquisição dos comportamentos-alvo como tatos e nomeação, seja pela rotatividade de repertórios de falante (Greer, Yuan, \& Gautreaux, 2005; Nuzzolo-Gomes, \& Greer, 2004), seja pela rotatividade de repertórios de ouvinte e de falante (Fiorile, \& Greer, 2007; Santos \& Souza, 2016).

No estudo realizado por Fiorile e Greer (2007), os pesquisadores investigaram se quatro crianças com dois anos de idade e diagnósticos de TEA poderiam apresentar repertório de nomeação após o ensino por MEI, quando haviam falhado em apresentar nomeação após o ensino de tato puro. O experimento consistiu em uma fase pré-experimental para avaliar a nomeação para os estímulos dos conjuntos, teste de matching de identidade, teste de ouvinte, teste de tato impuro, ensino de tato puro, teste de ouvinte e de tato impuro. O ensino estruturado por MEI colocou em rotação respostas de matching auditivo-visual, ouvinte e tato puro. Foram realizadas 18 tentativas por operante para um conjunto de estímulos, sendo que outro conjunto era inserido caso o participante não apresentasse nomeação. Os resultados demonstraram para os quatro participantes que apenas o ensino de tato não foi suficiente para emergência da nomeação; contudo, após o ensino por MEI o repertório-alvo foi demonstrado para as quatro crianças.
Ainda no mesmo ano, Greer et al. (2007) compararam a emergência da nomeação pelo ensino por MEI e pelo ensino de um único operante por sessão (SEI) em oito crianças com desenvolvimento atípico e com idade entre três e cinco anos. O ensino por MEI consistiu na rotação entre respostas de matching de identidade, ouvinte, tato puro e tato impuro. O SEI foi definido por ensino individual de operantes de ouvinte e teste de falante. Os resultados apontaram que as crianças que receberam ensino por MEI demonstraram aquisição da nomeação, enquanto o grupo que recebeu ensino por SEI não demonstrou a aprendizagem deste repertório.

Como demonstrado pelas pesquisas relatadas, o MEI tem sido um procedimento utilizado e frequentemente efetivo para ensino de habilidades verbais para crianças com desenvolvimento atípico, e especialmente o TEA. Contudo, existem poucas pesquisas envolvendo esse procedimento de ensino (Guerra, 2015). Além disso, a análise dos estudos tem demonstrado que uma exposição ao MEI somente tem sido efetiva para a emergência de um novo operante nos casos de crianças com desenvolvimento típico (Galic, \& Greer, 2011) e o ensino de ecoico em rotatividade com outros operantes tem sido adotado em pesquisas com participantes com diagnóstico de deficiência auditiva (Rique, Guerra, Borelli, Oliveira, \& Almeida-Verdu, 2017)

Devido à necessidade de realizar mais pesquisas com o ensino estruturado por MEI e considerando-se a importância da aquisição dos operantes de falante e ouvinte bem com as condições sob as quais se integram, isto é, se tornam interdependentes, a presente pesquisa foi realizada. O objetivo foi investigar $o$ efeito do ensino por MEI sobre o estabelecimento e integração entre os repertórios de ouvinte e de falante (ecoico, tato e mando) favorecendo a emergência de respostas verbais vocais não diretamente ensinadas em duas crianças com TEA. A investigação, por um lado, foi baseada no procedimento de Greer et al. (2005); por outro, algumas modificações foram realizadas com vistas a obter avanços científicos em relação aos estudos citados anteriormente. As diferenças adotadas foram: reduzir o número de respostas solicitadas por operante e o número de estímulos de cada conjunto (de cinco para três) para investigar se a diminuição no custo de respostas para o participante garante que a efetividade do procedimento permaneça; a manutenção dos mesmos passos para o pro- 
cedimento de ensino; e mensurar o efeito da inserção do operante ecoico nas fases de ensino, uma vez que foi um comportamento utilizado em outros estudos apenas como prompt.

\section{Método}

\section{Participantes}

Participaram dois meninos com diagnóstico médico de TEA, com reconhecidos atrasos no desenvolvimento intelectual, da linguagem e com comportamento heteroagressivo. Enry apresentava como comorbidade Paralisia Cerebral, estava com oito anos e frequentava uma escola comum no ensino fundamental. Possuía repertórios verbais de mando por meio de trocas de figuras, respostas textuais para todas as vogais e para o número um e repertório intermediário de ouvinte (imitar ações, seguir instruções simples, realizar matching de identidade e arbitrário) de acordo com a Avaliação de Comportamento Verbal (Barbera, \& Rasmussen, 2007). A criança recebia semanalmente atendimento grupal multidisciplinar (fisioterápico, psicológico, fonoaudiológico e com terapeuta ocupacional) em uma instituição para pessoas com deficiência. Enry havia sido exposto anteriormente ao ensino de repertórios de ouvinte (ouvir baseado em seleção) e de falante (ecoico, tato e mando) por um procedimento de ensino estruturado em tentativas discretas e por operantes únicos (single exemplar instruction); todavia, os resultados obtidos não foram satisfatórios, pois não houve aquisição dos operantes-alvo. Na avaliação pelo Verbal Behavior Milestones Assessment and Placement Program VBMAPP (Sundberg, 2008), pontuou 14 no nível 1.

Samy estava com sete anos e frequentava uma escola especial para pessoas com TEA, que baseava o ensino no método Treatment and Education of Autistic and Related Communication-Handicapped Children (TEACCH). Apresentava repertórios verbais restritos, sendo que para fazer pedidos utilizava as pessoas do entorno como instrumento (puxava as pessoas pela mão e levava até o item desejado) e apresentava repertório inicial de ouvinte (imitava duas ações, seguia instruções como "olhe para mim" e "senta") de acordo com a Avaliação de Comportamento Verbal (Barbera \& Rasmussen, 2007). Na avaliação pelo VBMAPP (Sundberg, 2008), pontuou 7 no nível 1.
Os critérios de inclusão adotados foram apresentar diagnósticos de TEA, operantes verbais fracamente estabelecidos e presença de comportamentos requisitos para receber ensino, como permanecer sentado, estabelecer contato visual e seguir comandos simples (Greer, \& Ross, 2008).

Previamente à coleta de dados, foi assinado o Termo de Consentimento Livre e Esclarecido pela responsável pela criança, em conformidade com o projeto previamente aprovado pelo Comitê de Ética em Pesquisa da Faculdade de Ciências da Universidade Estadual Paulista - Unesp (Número do Parecer: 393.839; Data da Relatoria: 12/09/2013).

\section{Instrumentos, materiais estímulos e condições experimentais}

Durante as sessões de avaliação e de ensino foram utilizados uma câmera para filmagem, diário para anotação dos dados, uma mesa para apresentação dos estímulos, cadeiras para o participante e pesquisadora. Previamente ao início de cada sessão eram realizadas avaliações de preferência de estímulos reforçadores, por meio da exposição de estímulos múltiplos sem reposição (Carr, Nicolson, \& Higbee, 2000). As sessões foram realizadas nas casas das crianças, em seus respectivos dormitórios, em média cinco vezes por semana, duas sessões por dia, com duração de vinte minutos cada.

Para a caracterização do repertório inicial foram adotados os instrumentos Ferramenta de Avaliação de Comportamento Verbal (Adaptado de Barbera, \& Rasmussen, 2007), via relato das responsáveis pelas crianças, e verifica a ocorrência e frequência das categorias de comportamento verbal e de comportamento de ouvinte. Também foi adotada a VBMAPP (Sundberg, 2008), escalas de mando, tato, ouvinte, ecoico, comportamento vocal espontâneo e intraverbal, via observação e testagem direta; foi adotado o Nível 1 (até 18 meses de idade)

Foram selecionados para o ensino três conjuntos de estímulos tridimensionais apresentados na Tabela 1. O conjunto 1 foi composto por brinquedos, o conjunto por comestíveis e o conjunto 3 por materiais escolares. Conforme a Tabela 1, foram selecionados mais estímulos para Samy no conjunto 2. Isso ocorreu devido à necessidade de realizar rotas alternativas de ensino para esse participante, que serão mais bem descritas nos resultados. 


\section{Procedimento de avaliação e ensino de habilidades de ouvinte e falante}

Os participantes foram expostos a procedimentos de avaliação e de ensino dos operantes de ouvir baseado em seleção, ecoico, tato e mando.

\section{Avaliação inicial}

A avaliação consistiu em mensurar antes do procedimento de ensino os operantes ouvinte, ecoico, tato e mando para os três conjuntos de estímulos de acordo com a Tabela 1. As sondagens foram realizadas três vezes consecutivas para cada conjunto após pequenos intervalos, sendo cada avaliação composta por quatro tentativas para cada estímulo do conjunto, sendo uma para cada operante (ouvinte, ecoico, tato e mando). Assim, o pré-teste foi composto por 36 oportunidades de resposta para cada conjunto, sendo 12 para cada objeto.

A avaliação do comportamento de ouvir foi realizada pelo procedimento de matching-to-sample auditivo-visual. Consistiu na apresentação dos três estímulos de um conjunto e era solicitado à criança que apontasse um, dentre os três, pela frase "Aponte (nome do objeto)"; em sucessivas tentativas os itens eram alternados de posição, garantindo que a resposta de seleção não fosse controlada pela posição do objeto. O comportamento ecoico foi avaliado solicitando ao participante que repetisse o nome de um dos objetos que era ditado pela experimentadora "Diga (nome do objeto)", porém na ausência deste. Para a avaliação do tato, o objeto era apresentado à frente da criança, e era perguntado "O que é isso?". Por fim, para testar o mando, o item era colocado à frente da criança e quando ela tentava alcançar o estímulo, ele era retirado do seu campo visual e era questionado "O que você quer?". Cada instrução foi fornecida após a pesquisadora ter garantido a atenção da criança, e era realizado um breve intervalo entre as tentativas (cerca de cinco segundos).

$\mathrm{Na}$ avaliação as respostas dos participantes não foram seguidas de consequências programadas para acertos ou erros, todavia, para que as crianças continuassem se mantendo na atividade e para evitar os efeitos da extinção, elas tinham acesso a elogios e outros reforçadores quando comportamentos adequados eram emitidos (como sentar, permanecer sentado, olhar e imitar).

\section{Ensino}

Os operantes-alvo de ensino foram ouvir (tarefas de ouvir baseado em seleção) ecoico, tato e mando, realizados em tentativas discretas, assim como nas fases de avaliação. Diferentemente da avaliação, consequências programas foram fornecidas após respostas de acertos e de erros. Para as respostas corretas era disponibilizado acesso ao item reforçador e elogios (“Ótimo!", “Você é muito bom!", “Demais!", “Parabéns!”), além do item identificado pela avaliação de preferência. Para garantir a operação estabelecedora de privação, a família era instruída a manter os objetos fora de alcance da criança por pelo menos uma hora antes do ensino.

Caso a resposta-alvo não fosse emitida, prompts eram fornecidos como procedimentos de correção eram aplicados. Para a resposta de selecionar um estímulo visual condicionada à palavra ditada pela experimentadora, o prompt era ajuda física; em sucessivas tentativas a ajuda física era esmaecida por passos de fading out, retirando a intensidade da ajuda (ajuda total, ajuda parcial, ajuda mínima, sem ajuda). Para os comportamentos vocais o prompt era a pista ecoica; se o participante repetisse a palavra ditada pelo experimentador, esta poderia ser colocada sob controle do objeto (tato) ou da operação estabelecedora (mando).

Tabela 1

Estímulos discriminativos utilizados por participante para cada conjunto.

\begin{tabular}{lccc}
\hline & CONJUNTO 1 & CONJUNTO 2 & CONJUNTO 3 \\
\hline \multirow{2}{*}{ ENRY } & Cavalo & Mortadela & Lápis \\
& Bola & Coca & Caderno \\
& Viola & Chocolate & Giz de cera \\
SAMY & Bola & Bis, Chocolate & Lápis \\
& Mola & Salgadinho, TicTac & Caderno \\
& Piano & Bala & Giz de cera \\
\hline
\end{tabular}


O delineamento de ensino e testes consistiu em cinco fases apresentadas na Tabela 2 e melhor descritas a seguir.

Fase 1 - Ensino de ouvir baseado em seleção para o conjunto 1 e sondagem dos repertórios de falante para o conjunto 1

O ensino foi estruturado em nove tentativas, sendo que os três itens do mesmo conjunto eram dispostos à frente da criança, e era solicitado "Aponte (nome do objeto)". As tentativas com os três estímulos do conjunto eram randomizadas dentro de um mesmo bloco com nove tentativas.

Após o ensino do ouvir baseado em seleção pelo matching to sample auditivo-visual, era realizado um teste das respostas de falante não ensinadas (ecoico, tato e mando) para o mesmo conjunto de estímulos e assim verificar o efeito do ensino do comportamento de ouvinte sobre a emergência de comportamentos de falante. Cada operante foi testado em blocos com nove tentativas, sendo três oportunidades de resposta para cada estímulo. Independente de acertos ou erros o participante era exposto à Fase 2.

Fase 2 - Ensino de ouvir baseado em seleção, ecoico, tato e mando por MEI para o conjunto 2 e sondagem dos repertórios de falante para os conjuntos 1 e 3

O ensino consistiu em doze tentativas por sessão, sendo que, para cada objeto era solicitado quatro respostas (ouvir baseado em seleção, ecoico, tato e mando), controladas por estímulos diferentes (objeto, palavras ditadas, objeto, operação estabelecedora), tal como a proposta de estruturação por MEI que permite rotatividade entre repertórios de ouvinte e de falante em tentativas sucessivas. O MEI foi realizado de forma linear (Nuzzollo-Gomes, \& Greer, 2004), isto é, para cada objeto a sequência dos operantes solicitados foi a mesma, qual seja, ouvir baseado em seleção, ecoico, tato e mando.

O critério de aprendizagem estabelecido para ouvir baseado em seleção foi apresentar nove respostas corretas, independentes e consecutivas em uma sessão; quando o procedimento foi estruturado em MEI o critério foi emitir 12 respostas corretas, independentes e consecutivas em uma sessão ou 11 respostas em duas sessões consecutivas, por conjunto de estímulos.

Durante o ensino, as respostas vocais foram modeladas, com exigências gradativas do comportamento-alvo, sendo que no início quaisquer vocaliza- ções eram aceitas e reforçadas; em seguida era exigido ao menos uma sílaba da palavra-alvo; depois, duas sílabas e assim sucessivamente até que a resposta vocal com maior correspondência fosse emitida.

Após o ensino do ouvir baseado em seleção com estímulos do conjunto 2, as respostas vocais (ecoico, tato e mando) com estímulos dos conjuntos $1 \mathrm{e}$ 3 foram testadas; o objetivo foi verificar o efeito do ensino pelo MEI com o conjunto 2 sobre a emergência de operantes verbais vocais com os demais conjuntos. Para o conjunto 1, para o qual já havia sido treinado o ouvir, foi testado ecoico, tato e mando; para o conjunto 3, todos os operantes foram testados, de ouvir baseado em seleção e os vocais como ecoico, tato e mando. Independente de acertos ou erros, os participantes foram expostos à Fase 3.

Fase 3 - Ensino de ouvir baseado em seleção com o conjunto 3 e sondagem dos repertórios não ensinados para o conjunto 1 e 3

Semelhante à Fase 1, o ensino foi estruturado em nove tentativas, sendo que os três itens do conjunto 3 eram dispostos para o participante e solicitado respostas de ouvir baseado em seleção como "Aponte (nome do objeto)", sendo as tentativas com os três estímulos do conjunto 3 randomizadas dentro de um mesmo bloco com nove tentativas. Após o ensino do ouvir baseado em seleção com estímulos do conjunto 3 , foram realizados os testes dos repertórios vocais ainda não ensinados para os conjuntos 1 e 3 , quais sejam, ecoico, tato e mando. Independente de acertos ou erros os participantes foram expostos à Fase 4.

Fase 4 - Ensino do ouvir baseado em seleção, ecoico, tato e mando por MEI para o conjunto 1 e sondagem dos repertórios não ensinados para o conjunto 3

Semelhante à Fase 2, o ensino consistiu na apresentação rotativa de tentativas que demandavam repertórios de ouvinte e de falante na sequência ouvir baseado em seleção-ecoico-tato-mando com estímulos do conjunto 1 . Após o ensino, foram testadas as respostas de ecoico, tato e mando, que ainda não haviam sido ensinadas com estímulos do conjunto 3.

\section{Avaliação Final}

Esta fase objetivou avaliar, após o procedimento de ensino, os operantes ouvinte, ecoico, tato e mando para os três conjuntos de estímulos, de forma semelhante a realizada na avaliação inicial. 
Tabela 2

Delineamento de ensino e testes adotados e fase em que o MEI foi inserido.

\begin{tabular}{|c|c|c|c|c|c|}
\hline \multirow[b]{2}{*}{ Fase } & \multirow[b]{2}{*}{ Operante-alvo } & \multicolumn{2}{|c|}{ Ensino } & \multicolumn{2}{|l|}{ Sondagem } \\
\hline & & Inserção do MEI & Conjunto & Operante-alvo & Conjunto \\
\hline Avaliação Inicial & & & & $\begin{array}{l}\text { Ouvir, ecoico, tato e } \\
\text { mando }\end{array}$ & 1,2 e 3 \\
\hline Fase 1 & Ouvir & - & 1 & Ecoico, Tato e Mando & 1 \\
\hline \multirow[t]{2}{*}{ Fase 2} & $\begin{array}{l}\text { Ouvir, ecoico, } \\
\text { tato e mando }\end{array}$ & MEI & 2 & Ecoico, Tato e Mando & 1 \\
\hline & & & & $\begin{array}{l}\text { Ouvir, Ecoico, Tato e } \\
\text { Mando }\end{array}$ & 3 \\
\hline \multirow[t]{2}{*}{ Fase 3} & Ouvir & & 3 & Ecoico, Tato e Mando & 1 \\
\hline & & & & Ecoico, Tato e Mando & 3 \\
\hline Fase 4 & $\begin{array}{l}\text { Ouvir, ecoico, } \\
\text { tato e mando }\end{array}$ & MEI & 1 & Ecoico, Tato e Mando & 3 \\
\hline Avaliação final & & & & $\begin{array}{l}\text { Ouvir, ecoico, tato e } \\
\text { mando }\end{array}$ & 1,2 e 3 \\
\hline
\end{tabular}

\section{Variáveis dependentes}

As variáveis dependentes foram as respostas de verbais de ecoico, tato e mando emitidas pelos participantes.

\section{Variáveis independentes}

A variável independente foi o procedimento de instrução por MEI.

\section{Procedimento de análise dos dados}

Os dados foram analisados pela quantidade de acertos obtidos na avaliação inicial (número de respostas corretas), nas sondagens sucessivas intercaladas com os procedimentos de ensino e na avaliação final. Durante as tarefas de ensino os acertos nos operantes-alvo foram organizados em curvas de frequência acumulada nas sucessivas sessões de ensino.

\section{RESULTADOS}

A Figura 1 apresenta a quantidade de acertos de respostas de ouvinte, de ecoico, tato e mando pelos participantes na Avaliação Inicial (barras cinzas) e Avaliação Final (barras pretas). De acordo com a Figura 1, o participante Enry demonstrou um aumento no número de respostas para todos os conjuntos de estímulos e para todos os operantes-alvo após a exposição ao ensino; o participante Samy apresentou maior número de respostas para o operante ouvinte no conjunto 2, para ecoico em todos os conjuntos, para tato no conjunto 3 para mando nos conjuntos 2 e 3 .

A Figura 2 apresenta a frequência acumulada de acertos nas etapas de ensino de ouvinte apenas e de todos os operantes de ouvir e falar via MEI para Enry. No treino de ouvinte com estímulos do conjunto 1 , Enry apresentou o critério de acertos na quarta sessão. No ensino por MEI com o conjunto 2, o critério deveria ser demonstrado para todos os operantes; como envolveu repertório expressivo, o critério de acertos envolvendo diferenciação entre os operantes, com uma unidade silábica foi obtido após 15 sessões; ao exigir duas unidades silábicas diferenciadas na emissão de ecoico, tato e mando, o critério foi obtido na $21^{\text {a }}$ sessão. Em relação a ensino de ouvir baseado em seleção para conjunto 3, o critério de acertos foi obtido após quatro sessões. Para ensino por MEI com estímulos do conjunto 1 o critério de acertos foi obtido após 14 sessões com uma unidade silábica de diferenciação e após 19 sessões para diferenciação com duas unidades silábicas, reduzindo o número de sessões de treino necessárias se comparado ao ensino por MEI para o conjunto 2.

A Figura 3 apresenta a frequência acumulada de acertos nas sessões de ensino para Samy em um total de 51 sessões. Para o ensino de ouvir com o conjunto 1 foram necessárias cinco sessões até a obtenção do critério de acertos. $\mathrm{O}$ ensino por MEI, realizado com o conjunto 2 teve diversas intercorrências (sinalizadas na figura e pelos asteriscos) que podem ter pre- 
judicado o desempenho do participante. $\mathrm{O}$ asterisco na sessão 11 sinaliza uma pausa que foi realizada no ensino devido à ausência da pesquisadora por duas semanas. Quando o ensino foi retomado na sessão 12 , os familiares relataram que durante esse período sem intervenção a criança havia apresentado um episódio convulsivo.

Por prescrição médica foi iniciado o uso de medicação anticonvulsiva, que permaneceu até a
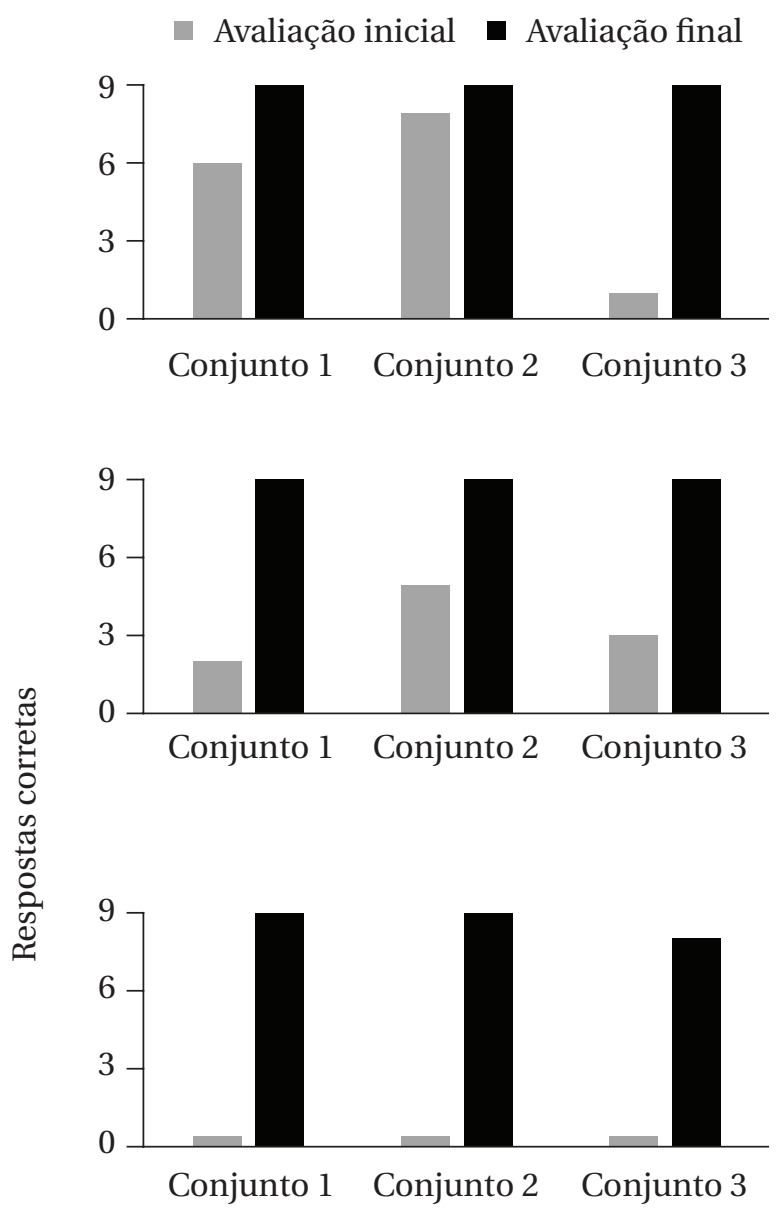

Conjunto 1 Conjunto 2 Conjunto 3 sessão 38. A partir do início da medicação, a criança tornou-se apática, sem mesmo apresentar os pré-requisitos que estavam sendo apresentados anteriormente, como olhar após a instrução "olhe para mim". Embora nesse período tenha apresentado apenas seis respostas para ouvir baseado em seleção, seis para tato e seis para mando, o operante ecoico continuava sendo emitido e obteve 32 respostas corretas, nesse período.

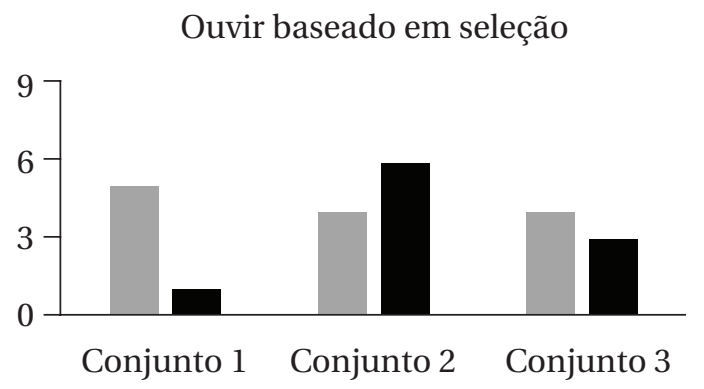

Ecoico

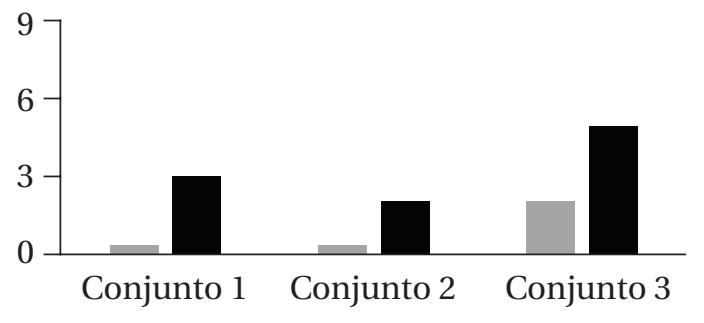

Tato

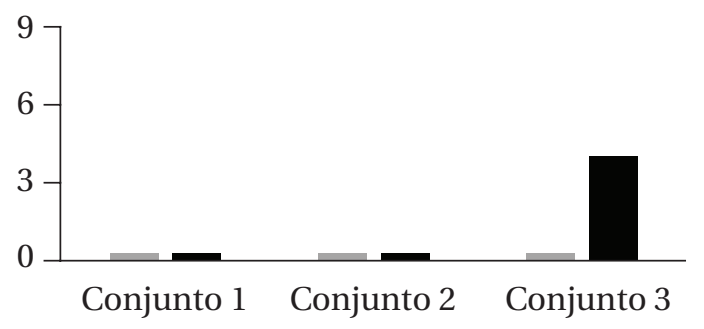

Mando
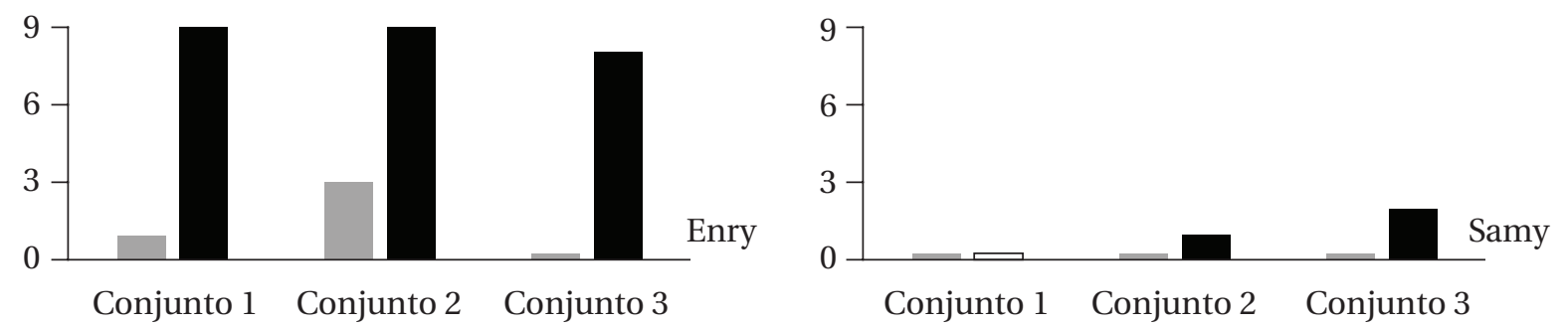

Figura 1

Quantidade de acertos nos operantes verbais na Avaliação Inicial e Avaliação Final para os dois participantes. 


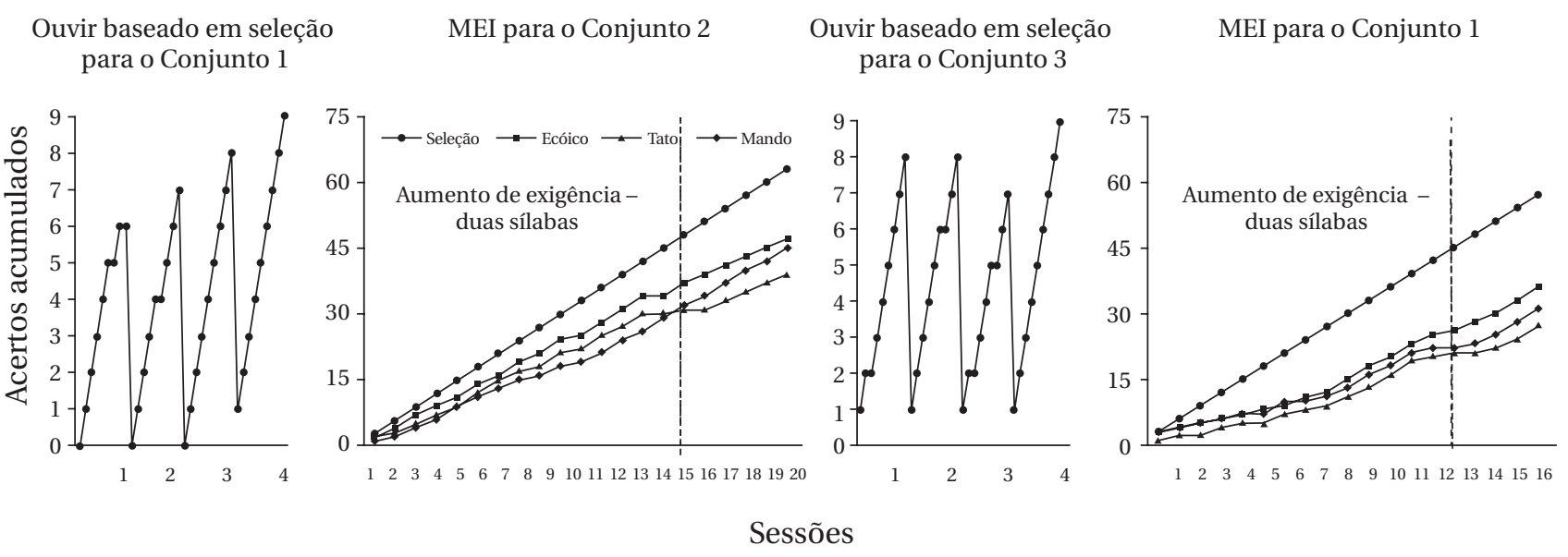

Figura 2

Frequência acumulada de respostas para o ensino de ouvir baseado em seleção para os conjuntos 1 e 3, e ensino de MEI para os conjuntos 2 e 1 para o participante Enry.
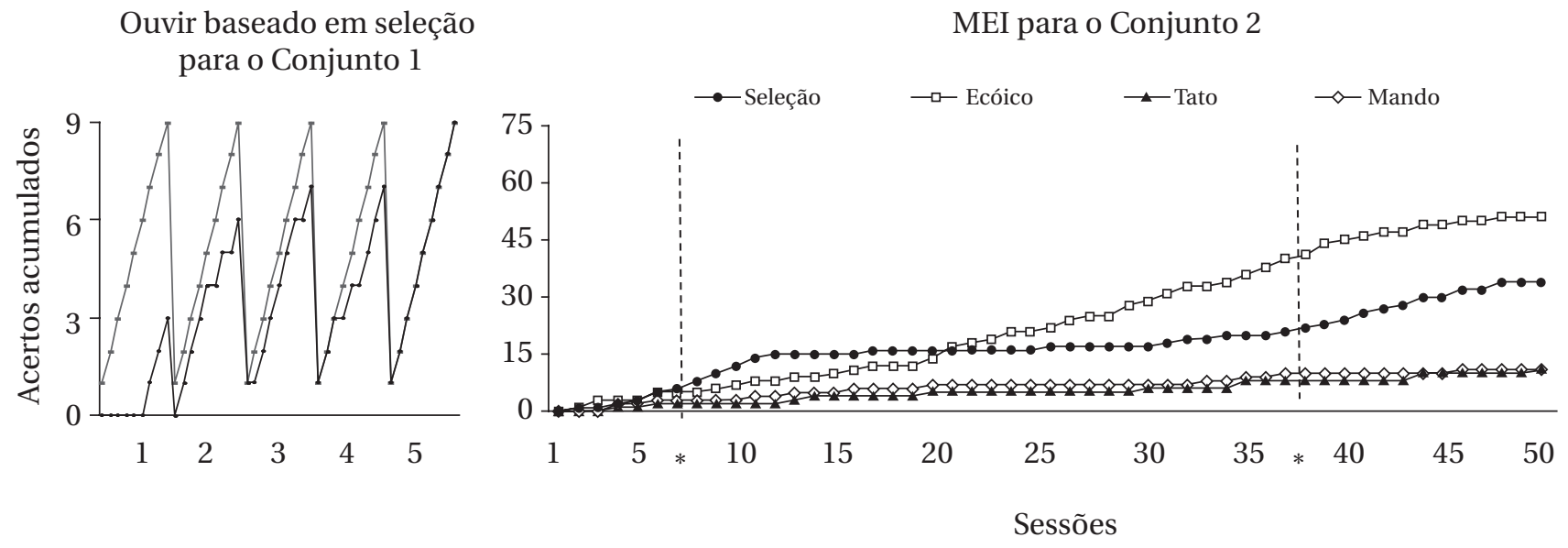

MEI para o Conjunto 2

Figura 3

Frequência acumulada de respostas de ouvir baseado em seleção para o Conjunto 1 e operantes ouvir e de tato, ecoico e mando via MEI para o conjunto 2 para o participante Samy.

Após a retirada da medicação, optou-se pela alteração dos estímulos do conjunto 2 , sendo que os familiares relataram que bala tipo "Tic-Tac" e chocolate eram os comestíveis mais reforçadores na ocasião. Nas 13 sessões seguintes (39 a 51), houve aumento na frequência de acertos acumulados para todos os operantes: ouvinte (13), ecoico (11), tato (3) e mando (1). As respostas consideradas como corretas para Samy foram apenas produção oral de vogais, todavia diferenciadas para cada estímulo, como "e" para chocolate tipo Bis, "a" para bala e "o" para salgadinho. Devido ao baixo desempenho da criança no ensino de MEI para o conjunto 2, o procedimento foi encerrado na sessão 51, e em seguida foi realizada a Avaliação Final.

A Figura 4 apresenta o efeito do ensino de seleção e por MEI, sobre a emissão de operantes de ouvir e de falar (ecoico, tato e mando) com os estímulos dos conjuntos 1 (parte superior), 2 (parte central) e 3 (parte inferior) para Enry. Como se pode observar na figura, somente o ensino de ouvir com estímulos do conjunto 1 não foi condição para a emergência dos operantes expressivos como ecoico, tato e mando. Após o ensino por MEI com os estímulos do conjunto 2, houve aumento do número de respostas de ecoico, tato e mando, não ensinadas, para estímu- 


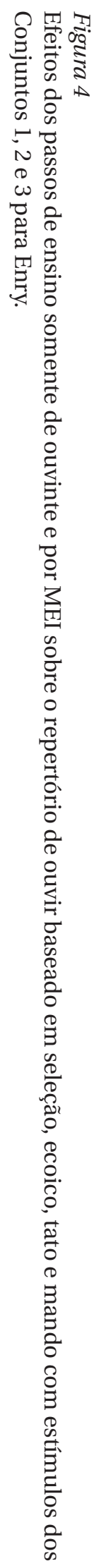

Número de acertos
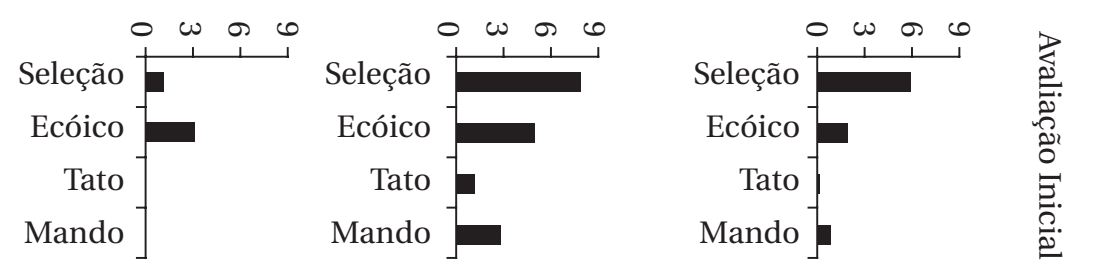

Fase 1 - Ouvinte - Conj 1
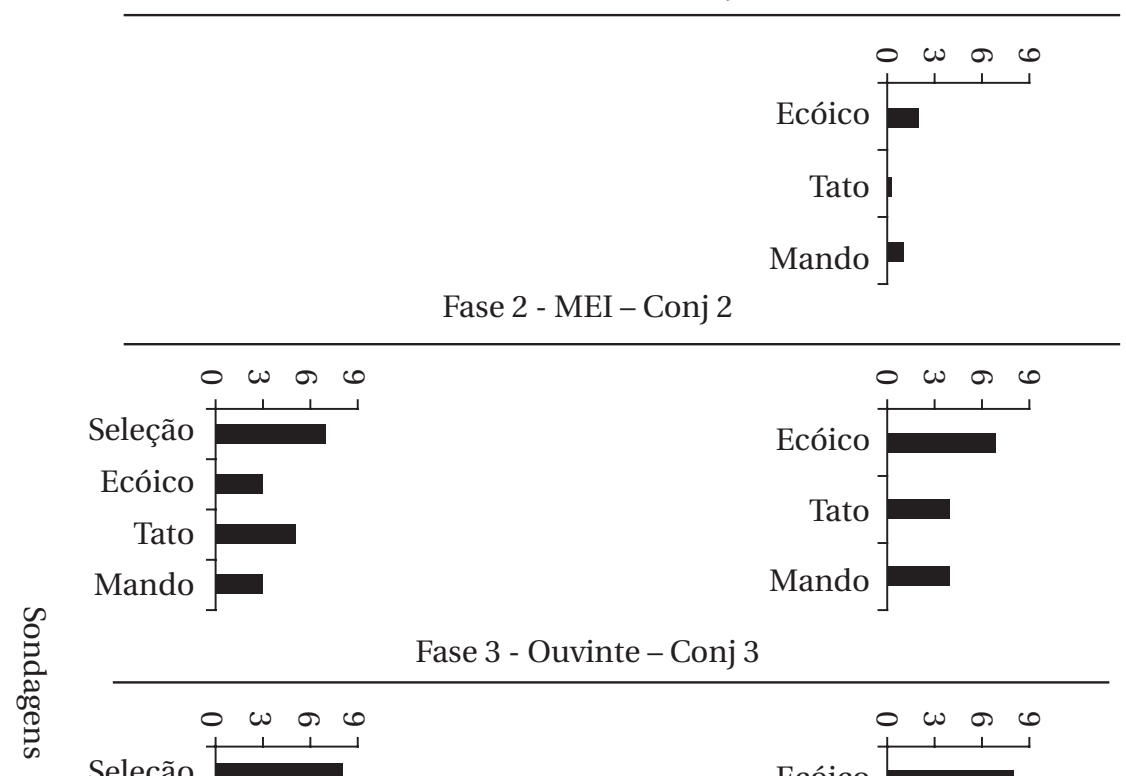

Fase 3 - Ouvinte - Conj 3

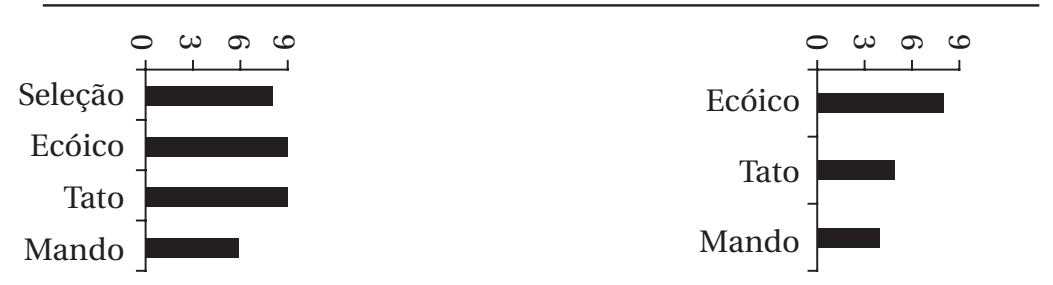

Fase 4 - MEI - Conj 1
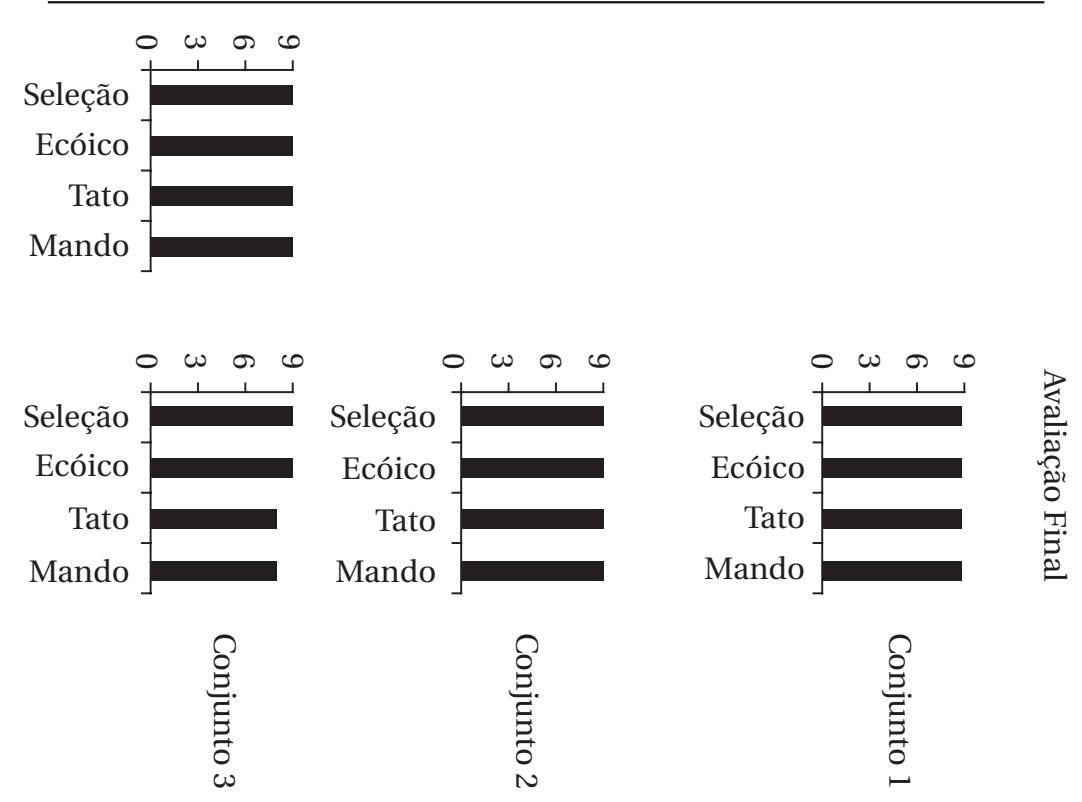
los do conjunto 1 e para respostas de ouvinte, ecoico, tato e mando para estímulos do conjunto 3 , também não ensinadas. Após o ensino de ouvinte com estímulos do conjunto 3, passou a ser observada um número de respostas maior dos operantes expressivos não ensinados diretamente com estímulos do mesmo conjunto.

O número de respostas corretas dos operantes com estímulos do conjunto 1 demonstraram tendência a aumentar. Em seguida, Enri foi exposto ao ensino por MEI com estímulos do conjunto 1, e após o ensino por MEI com esse segundo conjunto de estímulos, as respostas não ensinadas para o conjunto 3 atingiram a precisão. No pós-teste geral, Enri obteve precisão para os operantes de ouvir e falar (ecoico, tato e mando) com os três conjuntos de estímulos.
A Figura 5 apresenta os efeitos dos passos de ensino de ouvir baseado em seleção e por MEI sobre os operantes de ouvir e falar com estímulos dos conjuntos 1, 2 e 3 para o participante Samy. O primeiro ensino realizado foi o de ouvir baseado em seleção com estímulos do conjunto 1; em seguida, testou-se os efeitos da aquisição do operante ouvinte sobre os comportamentos de falante do mesmo conjunto. $\mathrm{O}$ resultado da sondagem demonstrou que a criança não emitiu nenhum operante verbal vocal. Após o ensino por MEI com estímulos do conjunto 2, embora tenha aumentado o número de ecoicos emitidos, os operantes de tato e mando continuaram com baixa ocorrência de acertos com este conjunto de estímulos. No geral, foi possível observar na avaliação final um discreto aumento no número de respostas cor-

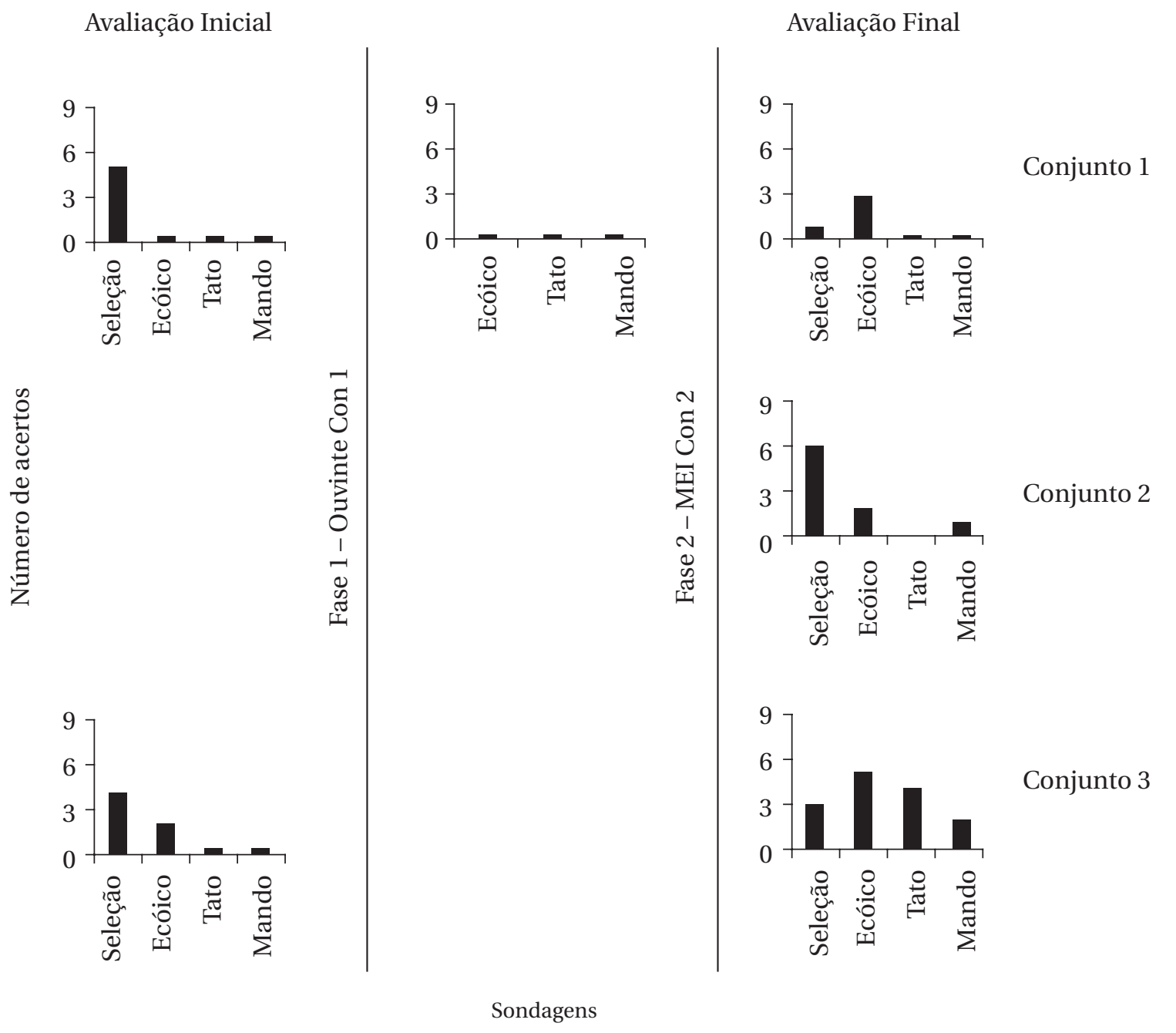

Figura 5

Efeitos dos passos de somente ouvir e ensino por MEI sobre o repertório de ouvir baseado em seleção, ecoico, tato e mando, com estímulos dos Conjuntos 1, 2 e 3 para Samy. 
retas para todos os operantes com todos os conjuntos: para ouvir baseado em seleção houve aumento no conjunto 2 (duas respostas); para ecoico ocorreu aumento para todos os conjuntos (três respostas para os conjuntos 1 e 3 e duas para o conjunto 2); para tato observou-se o aumento no conjunto 3 (quatro respostas) e para mando houve aumento nos conjuntos 2 (uma respostas) e 3 (duas respostas).

\section{Discussão}

O objetivo desse estudo foi verificar os efeitos do MEI sobre o estabelecimento e integração entre os repertórios de ouvinte e de falante (ecoico, tato e mando) para duas crianças com TEA e investigar seus efeitos sobre a emergência de respostas verbais vocais não ensinadas. Os resultados demonstraram que, embora os dois participantes passaram a emitir os operantes de ouvir e de falar com maior frequência, se comparados com a linha de base, o procedimento foi efetivo com um dos participantes.

De maneira geral os dois participantes aprenderam o repertório de ouvinte. Todavia, o ensino de ouvinte, isoladamente, não garantiu a emergência dos operantes verbais expressivos e que não foram ensinados diretamente (ecoico, tato e mando). Somente após o treino com MEI (conjunto 2) que o treino de ouvinte (conjunto 3) que Enry demonstrou como resultados o maior número de acertos em respostas de falante (ecoico, tato e mando).

Os resultados demonstrados por Enry replicam dados da literatura em relação a independência funcional entre os operantes de ouvir e de falar com diferentes populações (Guess, 1969; Pereira et al., 2018; Skinner, 1957) e ao potencial do MEI como condição para estabelecer controle compartilhado de estímulos e emergência sobre operantes não ensinados (Greer at al., 2005; Pereira et al., 2018). Sobre a independência funcional entre ouvir e falar, o ensino do comportamento de ouvir isoladamente não garantiu a geração de novas respostas verbais de falante, pois conforme demonstrado pelos resultados, mesmo após a aquisição do comportamento de ouvir baseado em seleção, tal repertório não teve praticamente efeito sobre a geração de novas respostas verbais (Greer et al., 2005). Quanto ao efeito do MEI para estabelecer controle compartilhado entre estímulos e gerar novas respostas verbais, observou-se que, após a exposição do participante ao ensino de diferentes operantes verbais com estímulos de um conjunto e promovendo a rotação entre diferentes respostas de ouvir e falar e entre diferentes controle de estímulos (auditivo e visual), as respostas se tornaram interdependentes como observado em outros estudos (Greer et al., 2005; Greer, Nirgudkar, \& Park, 2003; Luke et al., 2011; Pereira et al., 2018).

Considerando o uso do MEI como forma de garantir controle conjunto de estímulos, a pesquisa na qual este estudo foi baseado (Greer et al., 2005), apresenta aspectos convergentes e divergentes aos adotados nesta pesquisa. Os pontos convergentes são (1) a rotatividade entre respostas de falante e ouvinte durante o ensino por MEI, (2) o uso de três conjuntos de estímulos para o ensino e 3) o delineamento geral (ambos com as mesmas fases). Quanto aos pontos divergentes, pode-se citar, sobretudo, (1) os operantes demandados; Greer et al. (2005) utilizou matching de identidade, ouvir baseado em seleção, tato puro e tato impuro; a presente pesquisa ensinou ouvir baseado em seleção, ecoico, tato e mando); o ecoico tem sido colocado em rotatividade com outros operantes em estruturas de ensino via MEI pelo nosso grupo (por exemplo: Pereira et al., 2018; Rique et al., 2017) e tem se demonstrado efetivo não só no estabelecimento de resposta nova, mas no aumento da acurácia desta em participantes com deficiência auditiva; (2) o repertório de entrada dos participantes foi outra diferença importante, pois no presente estudo participaram duas crianças, uma com repertório verbal mínimo e outra com ausência de repertórios verbais, enquanto no estudo de Greer et al. (2005) participaram três crianças com repertórios básicos de ouvinte e falante); (3) a quantidade de estímulos por conjunto sendo a presente pesquisa com um número reduzido; foi possível verificar que a redução no número de estímulos de cada conjunto não interferiu sobre a ampliação dos repertórios dos participantes.

Outros estudos estão de acordo com os dados obtidos, pois demonstram que a aprendizagem de um operante pode gerar respostas distintas após arranjo particular de contingências de ensino, mesmo sem treino direto em pessoas com déficits de aprendizagem (Fiorile, \& Greer, 2007; Greer et al., 2003; 2005; Greer, Yuan, \& Gautreaux, 2005; Luke et al., 2011; Nuzzolo-Gomez, \& Greer, 2004).

Há estudos na literatura que demonstram a efetividade parcial do MEI para ensino de repertórios verbais, como ocorreu neste estudo para Samy. Santos e Souza (2016) ao propor o ensino por MEI (mat- 
ching de identidade, matching auditivo-visual e tato) comparando o uso de estímulos bi e tridimensionais para quatro crianças com TEA, obteve como resultado a emergência de nomeação apenas para dois participantes. Embora Samy tenha iniciado o ensino de MEI apresentando mais respostas de ouvinte (matching auditivo-visual), na sessão 21 a emissão de ecoico passou a ser mais frequente, inclusive que o comportamento de ouvinte. É de suma importância valorizar o aumento nas respostas ecoicas em todos os conjuntos, uma vez que é fundamental para aquisição de tato e outros comportamentos complexos (Skinner, 1957). Uma possível explicação para o aumento nas respostas ecoicas pode ser pela necessidade de prompts (ecoico) no ensino dos operantes de tato, mando e do próprio ecoico. Isso pode ter facilitado a aprendizagem do comportamento de ecoar, por overtraining (Catania, 1965).

Outra possibilidade de discussão dos resultados de comportamento de falante dos dois participantes é que o treino de tato e mando foi realizado com diferentes prompts ecoicos, o que era mais uma oportunidade para que o participante ecoasse. Pesquisas que estruturaram o ensino exigindo respostas-alvo encadeadas com respostas ecoicas demonstraram que o procedimento teve efeito sobre a aquisição de outros comportamentos verbais, como treino de matching auditivo-visual com encadeamento de respostas ecoicas (Koegel, Dunlap, Richman, \& Dyer, 1981; Hawkins, Kingsdorf, Charnock, Szabo, \& Gautreox, 2009). Para Enry o MEI garantiu a extensão do controle de estímulos do ecoico para outros operantes verbais como o mando e o tato; para Samy, não.

Como demonstrado na seção de resultados, os treinos de ouvinte tiveram pouco efeito sob as respostas não ensinadas para os participantes em comparação ao MEI. Assim como apontado por Petursdottir, Lepper e Peterson (2014), uma limitação dos treinos de ouvinte é que eles podem não ser efetivos em gerar comportamento vocal. Todavia, a depender das condições sob as quais é realizado, pode afetar respostas de falante, como por exemplo, da solicitação de respostas colaterais, e entre elas, a resposta ecoica.

Embora a aquisição dos repertórios de falante e ouvinte ocorra de forma independente, o controle conjunto de estímulos e a interdependência entre os dois comportamentos podem ser obtidas pelo MEI (Greer, \& Ross, 2008). Esse estudo permitiu que relações de interdependência entre os repertórios de ouvinte e falante fossem estabelecidas e demonstrou os efeitos dessa interdependência sobre os repertórios de ouvinte, ecoico, mando e tato dos participantes, que são requisitos para a aprendizagem do comportamento de nomeação (Horne, \& Lowe, 1996). Assim, a integração entre ouvir e falar é essencial por permitir a aprendizagem de novos comportamentos complexos, como leitura e nomeação (Greer, \& Ross, 2008).

O procedimento desse estudo foi composto por diversas sondagens ao longo do ensino: pré-teste geral, após o ensino de matching auditivo-visual para o conjunto 1 , sondagem após o ensino por MEI para o conjunto 2, após o ensino de matching auditivo-visual para o conjunto 3, após o ensino de MEI para o conjunto 1 e pós-teste geral. Alguns estudos têm demonstrado os efeitos das sondagens entre as diferentes fases do ensino no incremento do comportamento-alvo (Fields, 1981, 1985; Lucchesi, Almeida-Verdu, \& Souza, 2018). Fields (1981) realizou uma pesquisa que teve por objetivo ensinar 16 universitários a identificar os nomes em braile das letras do alfabeto. Para investigar os efeitos dos testes durante o ensino, o pesquisador comparou dois grupos: para o grupo 1 a nomeação foi testada desde o começo do ensino e ao longo das diferentes etapas; para o grupo 2 foi testado somente após a metade do ensino. Os resultados demonstraram que o grupo que foi submetido a testes desde o começo do ensino, demandou um número menor de prompt para apresentar o critério de acertos. $\mathrm{O}$ autor discute que as sondas múltiplas podem ter contribuído para a melhora na obtenção dos resultados. Da mesma forma, a realização de sondagens múltiplas pode ter favorecido, nesse estudo, a aquisição de comportamentos verbais não diretamente ensinados para o participante Enry.

Em suma, o procedimento demonstrou-se efetivo para ampliar os repertórios verbais, comportamentos estes de relevância social, pois a ausência de linguagem afeta áreas importantes para o desenvolvimento como brincar, atividades escolares, resolução de problemas (Sundberg, 2007). Futuras pesquisas podem replicar os dados com mais crianças com TEA e com outras condições de atrasos no repertório linguístico para verificar a generalidade dos dados. Por outro lado, a solicitação de respostas de ecoico durante o treino de matching auditivo-visual pode ser controlada para verificar se alteraria o poder gerativo sobre comportamentos verbais. Além disso, a exigência de unidades silábicas também pode ser sistematizada 
para verificar a melhoria na inteligibilidade da fala (correspondência ponto a ponto com as convenções da comunidade verbal). Uma outra possibilidade de futuras investigações é identificar o número de vezes que se necessita realizar exposição do ensino por MEI para que a integração entre os operantes emerja.

\section{Referências}

Ahearn, L. M. (2012). Living language: An introduction to linguistic anthropology. Journal of The Royal Anthropological Institute, 18(4), 898-899. https://doi.org/10.2307/23321467

American Psychiatric Association - APA (2013). Diagnostic and statistical manual of mental disorders - DSM - 5. (5a ed.). Washington, DC: American Psychiatric Association.

Barbera, M. L., \& Rasmussen, T. (2007). The verbal behavior approach: How to teach children with autism and related disorders. London: Jessica Kingsley.

Carr, J. E., Nicolson, C., \& Higbee, T. S. (2000). Evaluation of a brief multiple-stimulus preference assessment in a naturalistic context. Journal of Applied Behavior Analysis, 33(3), 353-357. https://doi.org/10.1901/ jaba.2000.33-353

Catania, A. C. (1965). Interocular transfer of discriminations in the pigeon. Journal of the Experimaental Analysis Behavior, 8, 47-155. https://doi.org/10.1901/jeab.1965.8-147

Fields, L. (1981). Early and late introduction of probes and stimulus control acquisition in fading. Journal of Experimental Analysis Behavior, 36(3), 363-370. https://doi.org/10.1901/jeab.1981.36-363

Fields, L. (1985). Reinforcement of probe responses and acquisition of stimulus control in fading procedures. Journal of Experimental Analysis Behavior, 43(2), 235-241. https://doi.org/10.1901/jeab.1985.43-235

Fiorile, C. A., \& Greer, R. D. (2007). The induction of naming in children with no prior tact responses as a function of multiple exemplar histories of instruction. The Analysis of Verbal Behavior, 23, 71-87. https://doi.org/10.1007/ bf03393048

Gilic, L., \& Greer, R.D. (2011). Establishing naming in typically developing two-year-old children as a function of multiple exemplar speaker and listener experiences. The Analysis of Verbal Behavior, 27, 157-177. https://doi. org/10.1007/BF03393099

Green, G. (2001). Behavior analytic instruction for learners with autism: advances in stimulus control technology. Focus on Autism and Other DevelopmentalDisabilities, 16(2), 72-85.https://doi.org/10.1177/108835760101600203

Greer, R. D., Nirgudkar, A., \& Park, H. (2003). The effect of multiple exemplar instruction on the transformation of mand and tact functions. Paper Presented at the International Conference of the Association for Behavior Analysis, San Francisco, CA, USA.

Greer, R. D., \& Ross, D. E. (2008). Verbal behavior analysis: Inducing and expanding new verbal capabilities in children with language delays. Boston: Pearson.

Greer, R. D., Stolfi, L., Chavez-Brown, M., \& Rivera-Valdes, C. (2005). The emergence of the listener to speaker component of naming in children as a function of multiple exemplar instruction. The Analysis of Verbal Behavior, 21(1), 123-134. https://doi.org/10.1007/bf03393014

Greer, R. D., Stolfi, L., \& Pistoljevic, N. (2007). Emergence of naming in preschoolers: A comparison of multiple and single exemplar instruction. European Journal of Behavior Analysis, 8(2), 109-131. https://doi.org/10.1080/1502 1149.2007.11434278

Greer, R. D., Yuan, L., \& Gautreaux, G. (2005). Novel dictation and intraverbal responses as a function of a multiple exemplar instructional history. The Analysis of Verbal Behavior, 21(1), 99-116. https://doi.org/10.1007/ bf03393012

Guerra, B. T. (2015). Ensino de operantes verbais e requisitos para ensino por tentativas discretas em crianças com Transtorno do Espectro do Autismo (TEA). Dissertação de mestrado, Universidade Estadual Paulista, Bauru, SP, Brasil.

Guess, D. (1969). A functional analysis of receptive language e productive speech: acquisition of the plural morpheme. Journal of Applied Behavior Analysis, 2(1), 55-64. https://doi.org/10.1901/jaba.1969.2-55 
Hartman, E. C., \& Klatt, P. K. (2005). The effects of deprivation, presession exposure, and preferences on teaching manding to children with autism. The Analysis of Verbal Behavior, 21(1), 135-144. https://doi.org/10.1007/ bf03393015

Hawkins, E., Kingsdorf, S., Charnock, J., Szabo, M., \& Gautreaux, G. (2009). Effects of multiple exemplar instruction on naming. European Journal of Behavior Analysis, 10(2), 265-273. https://doi.org/10.1080/1502114 9.2009.11434324

Horne, P. J., \& Lowe, C. F. (1996). On the origins of naming and other symbolic behavior. Journal of the Experimental Analysis of Behavior, 65(1), 185-241. https://doi.org/10.1901/jeab.1996.65-185

Koegel, R. L., Dunlap, G., Richman, G. S., \& Dyer, K. (1981). The use of specific orienting cues for teaching discrimination tasks. Analysis and Intervention in Developmental Disabilities, 1(2), 187-198. https://doi.org/10.1016/02704684(81)90031-8

Lucchesi, F. D. M., Almeida-Verdu, A. C. M., \& Souza, D. G. (2018). Reading and speech intelligibility of a child with auditory impairment and cochlear implant. Psychology \& Neuroscience, 11(3), 306-316. https:/doi.org/10.1037/ pne0000139

Luke, N., Greer, R. D., \& Keohane, D. (2011). The emergence of autoclitic frames in atypically and typically developing children as a function of Multiple Exemplar Instruction. The Analysis of Verbal Behavior, 27(1), 141-156. https://doi.org/10.1007/bf03393098

Matson, J. L., \& Kozlowski, A. M. (2011). The increasing prevalence of autism spectrum disorders. Research in Autism Spectrum Disorders, 5(1), 418-425. https://doi.org/10.1016/j.rasd.2010.06.004

Michael, J. (1985). Two kinds of a verbal behavior plus and a possible third. The Analysis of Vebal Behavior, 3, 1-4. https://doi.org/10.1007/bf03392802

Novak, G., \& Pelaez, M. (2004). Child and adolescent development: A behavioral systems approach. Thousand Oaks: Sage.

Nunes, L. R. O. P. (1992). Métodos naturalísticos para o ensino da linguagem funcional em indivíduos com necessidades especiais. In E. Alencar (Org.), Novas contribuições da Psicologia aos processos de ensino e aprendizagem (pp. 71-96). São Paulo: Cortez.

Nuzzolo-Gomez, R., \& Greer, R. D. (2004). Emergence of untaught mands or tacts with novel adjective-object pairs as a function of instructional history. The Analysis of Verbal Behavior, 24, 30-47. https://doi.org/10.1007/ BF03392995

Pereira, F. S., Assis, G. J. A., Palheta Neto, F. X., \& Almeida-Verdu, A. C. M. (2018). Emergência de nomeação bidirecional em criança com implante coclear via Instrução com Múltiplos Exemplares (MEI). Revista Brasileira de Terapia Comportamental e Cognitiva, 20(2), 26-39. https://doi.org/10.31505/rbtcc.v20i2.1178

Petursdottir, A. I., Lepper, T. L., \& Peterson, S. P. (2014). Effects of collateral response requirements and exemplar training on listener training outcomes in children. Psychological Record, 64(4), 703-714. https://doi.org/10.1007/ s40732-014-0051-x

Ribeiro, D. M., Elias, N. C., Goyos, C., \& Miguel, C. F. (2010). The effects of listener training on the emergence of tact and mand signs by individuals with intellectual disabilities. The Analysis of Verbal Behavior, 26(1), 65-72. https://doi.org/10.1007/bf03393084

Rique, L. D., Guerra, B. T., Borelli, L. M., Oliveira, A. P., Almeida-Verdu, A. C. M. (2017). Ensino de comportamento verbal por múltiplos exemplares em uma criança com desordem do espectro da neuropatia auditiva: estudo de caso. Revista CEFAC, 19(2), 289-298. https://doi.org/10.1590/1982-021620171928516

Santos, E. L. N., \& Souza, C. B. A. (2016). Ensino de nomeação com objetos e figuras para crianças com autismo. Psicologia: Teoria e Pesquisa, 32(3), 1-10. https://doi.org/10.1590/0102-3772e32329

Skinner, B.F. (1957). Verbal behavior. New York: Appleton.

Sundberg, M. L. (2007). Verbal behavior. In J. O. Cooper, T. E. Heron, \& W. L. Heward, Applied behavior analysis (pp. 526-554). Upper Saddle River: Pearson.

Sundberg, M. L. (2008). Verbal behavior milestones assessment and placement program: The VB-MAPP. Concord: AVB Press. 


\section{Bárbara Trevizan Guerra}

Doutoranda em Psicologia do Desenvolvimento e Aprendizagem pela Universidade Estadual Paulista Júlio de Mesquita Filho, Bauru - SP. Brasil.

E-mail: barbaratguerra@gmail.com

(iD) https:// orcid.org/0000-0003-1590-3483

Ana Cláudia Moreira Almeida Verdu

Professora assistente, Doutora pela Universidade Estadual Paulista Júlio de Mesquita Filho. Membro do Instituto Nacional de Ciência e Tecnologia sobre Comportamento, Cognição e Ensino.

E-mail: ana.verdu@unesp.br

(iD) https:// orcid.org/0000-0001-5202-0263

Endereço para envio de correspondência:

Rua Alberto Segalla, 1-75, Sala 115, Cep 17012-634, Jardim Infante Dom Henrique, Bauru - SP. Brasil

Recebido 13/09/2017

Reformulado 13/06/2019

Aceito 11/01/2019

Received 09/13/2017

Reformulated 06/13/2019

Approved 01/11/2019

Recibido 13/09/2017

Reformulado 13/06/2019

Aceptado 01/11/2019

Esse artigo foi recorte da dissertação de mestrado da primeira autora, sob orientação da segunda autora. A primeira autora recebeu bolsa FAPESP (processo 2013/13028-0). A redação do artigo recebeu apoio do Instituto Nacional de Ciência e Tecnologia sobre Comportamento, Cognição e Ensino (FAPESP\#2014/50909-8 e CNPq\#465686/2014-1)

Como citar: Guerra, B. T., \& Almeida-Verdu, A. C. M. (2020). Ensino de Comportamento Verbal Elementar por Exemplares Múltiplos em Crianças com Autismo. Psicologia: Ciência e Profissão, 40, 1-17. https://doi.org/10.1590/1982-3703003185295

How to cite: Guerra, B. T., \& Almeida-Verdu, A. C. M. (2020).Teaching Elementary Verbal Behavior by Multiple Exemplar in Children with Autism. Psicologia: Ciência e Profissão, 40, 1-17. https://doi.org/10.1590/1982-3703003185295

Cómo citar: Guerra, B. T., \& Almeida-Verdu, A. C. M. (2020). Enseñanza del Comportamiento Verbal Elemental Mediante Múltiples Copias em Niños com Autismo. Psicologia: Ciência e Profissão, 40, 1-17. https://doi.org/10.1590/1982-3703003185295 